\title{
Quantitative image analysis as a diagnostic tool for identifying structural changes during a revival process of anaerobic granular sludge
}

\author{
A.A. Abreu, J.C. Costa, P. Araya-Kroff, E.C. Ferreira, M.M. Alves* \\ IBB-Institute for Biotechnology and Bioengineering, Centre of Biological Engineering, Universidade do Minho, Campus de Gualtar, \\ 4710-57 Braga, Portugal
}

\section{A R T I C L E I N F O}

\section{Article history:}

Received 3 May 2006

Received in revised form

22 December 2006

Accepted 14 January 2007

Available online 21 February 2007

Keywords:

Granular sludge

Quantitative image analysis

Specific methanogenic activity

Structural changes of anaerobic

granular sludge

\begin{abstract}
A B S T R A C T
Due to unspecified operational problems, the specific acetoclastic activity (SAA) of the anaerobic granular sludge present in an industrial UASB reactor was considerably damaged (from 250 to less than $10 \mathrm{~mL} \mathrm{CH}_{4} @ S T P / g V S S . d$ ), significantly reducing the biogas production of that industrial unit. The hydrogenotrophic methanogenic activity exhibited a value of $600 \mathrm{~mL}$ CH4@STP/gVSS.d, the settling velocity was $31.4 \pm 9.8 \mathrm{~m} / \mathrm{h}$, the average equivalent diameter was $0.92 \pm 0.43 \mathrm{~mm}$, and about $70 \%$ of the VSS were structured in aggregates larger than $1 \mathrm{~mm}$.

In order to study the recovery of the SAA, this sludge was collected and inoculated in a lab-scale expanded granular sludge blanket (EGSB) reactor. Ethanol was fed as the sole carbon source during a trial period of 106 days. Process monitoring included COD removal efficiency, methane production, and periodic determination of the specific methanogenic activity in the presence of acetate, propionate, butyrate, ethanol and $\mathrm{H}_{2} / \mathrm{CO}_{2}$. Quantitative image analysis allowed for information to be obtained on granular fragmentation/erosion and filaments release. During the first operational period, biogas production was mainly due to the hydrogenotrophic activity. However, after 40 days, the SAA steadily increased achieving a maximum value of $183 \pm 13 \mathrm{~mL}$ CH4@STP/gVSS.d. The onset of SAA recovery, granules breakdown and filaments release to the bulk occurred simultaneously. Further increase in SAA was accompanied by granular growth. In the last 25 days of operation, the size distribution was stable with more than $80 \%$ of projected area of aggregates corresponding to granules larger than $1 \mathrm{~mm}$ (equivalent diameter). Confocal images from FISH hybridized sections of the granules showed that after SAA recovery, the granules developed an organized structure where an acidogenic/acetogenic external layer was apparent. Granular fragmentation and increase of filaments in the bulk, simultaneously with the increase in the acetoclastic activity are described for the first time and might represent a structural response of granular sludge to promote the optimal substrate uptake at minimal diffusion limitations.
\end{abstract}

(c) 2007 Elsevier Ltd. All rights reserved.

*Corresponding author.

E-mail address: madalena.alves@deb.uminho.pt (M.M. Alves).

0043-1354/\$ - see front matter @ 2007 Elsevier Ltd. All rights reserved.

doi:10.1016/j.watres.2007.01.017 


\section{Introduction}

Anaerobic technology is recognized as an appropriate solution for the treatment of several types of industrial wastewaters. Granular sludge-based systems such as the upflow anaerobic sludge blanket (UASB) and the expanded granular sludge blanket (EGSB) are, by far, the best established and most applied high-rate anaerobic reactors (Lettinga, 1995). Stable and efficient operation of these anaerobic bioreactors is primarily dependent on the growth and maintenance of granular sludge containing all the microbial trophic groups necessary for complete mineralization of organic constituents present in the wastewater. Granular sludge has superior settling characteristics (superficial velocity up to $60 \mathrm{~m} / \mathrm{h}$ ) and a specific methanogenic activity (SMA) that can achieve $700 \mathrm{~mL} \mathrm{CH} \mathrm{CH}_{4} @ S T P / g$ VSS day (Hulshoff Pol et al., 2004).

Environmental factors such as temperature, $\mathrm{pH}$, presence of toxic compounds or absence of essential nutrients, selectively influence the growth and decay of the different trophic groups involved in anaerobic granular sludge. A granule comprises diverse bacterial morphotypes, varying from filamentous to round-shaped. Therefore, fluctuations in the SMA of the different trophic groups might affect the macrostructure and physical characteristics of the aggregates.

Decreasing computational costs have made it possible to use techniques such as quantitative image analysis for process monitoring. These techniques have already been applied in the morphological quantification of anaerobic sludge (Alves et al., 2000).

In some cases, after a process imbalance or when selection pressure is low, anaerobic granular sludge becomes dispersed with a large fraction of filamentous bacterial forms either attached or freely dispersed in the bulk (Hulshof-Pol et al., 2004). Quantification of this phenomenon has been presented only recently by Araya-Kroff et al. (2004). These authors proposed a new parameter to characterize anaerobic granular sludge that measures the ratio between the free (and protruding) filaments length and the projected area of aggregates (LfA). This parameter quantifies the degree of sludge dispersion/compaction and typically varies between 20 and $300 \mathrm{~mm}^{-1}$ (Araya-Kroff et al., 2004). LfA has also been shown to be an early warning sign of washout in an EGSB reactor fed with oleic acid (Amaral et al., 2004).

When operational problems occur at industrial scale, actions should be undertaken to overcome instability and inefficiency. It is particularly important to have quantitative methods that anticipate structural changes of anaerobic granular sludge that may affect process performance. When the inefficiency is related to the loss of acetoclastic activity, and because acetate is the precursor of approximately $70 \%$ of the methane produced in anaerobic digesters, a severe decrease in biogas production is observed.

Structural changes of anaerobic granular sludge during granular deterioration process have already been reported (Amaral et al., 2004). However, involvement of phenomena such as erosion, fragmentation, filaments release and growth of anaerobic granular sludge during a process of metabolic acclimation aiming to recover a target activity in anaerobic granular sludge have never been reported.
In this work, the relationship between structure and SMA is established for the first time during the enhancement of the specific acetoclastic activity in anaerobic granular sludge.

\section{Materials and methods}

\subsection{EGSB reactor, operational parameters, inoculum and substrate}

An plexiglas $11.4 \mathrm{~L}$ expanded granular sludge blanket (EGSB) reactor with a height of $2.22 \mathrm{~m}$ and a height to diameter ratio of 27 was operated continuously during 106 days with an hydraulic retention time (HRT) of $7.2 \mathrm{~h}$. Temperature was kept at $37 \pm 1^{\circ} \mathrm{C}$ by means of an external jacket for water circulation.

Ethanol was used as the sole organic substrate. The feed was decreased from $2900 \mathrm{mg}$ COD/h to $2200 \mathrm{mg}$ COD/h at day 20. Feed was pumped to the EGSB reactor from a solution of concentrated ethanol and alkalinity containers and diluted online with tap water. Sodium bicarbonate was used as the alkalinity source. Micro and macronutrients were added according to the following composition:

Macronutrients: $\mathrm{MgSO}_{4} .7 \mathrm{H}_{2} \mathrm{O}: 30 \mathrm{~g} / \mathrm{L} ; \mathrm{KH}_{2} \mathrm{PO}_{4}: 28.3 \mathrm{~g} / \mathrm{L} ; \mathrm{NH}_{4} \mathrm{Cl}$ : $170 \mathrm{~g} / \mathrm{L} .0 .6 \mathrm{~mL}$ of this solution was added per gram of COD fed.

Micronutrients: $\mathrm{FeCl}_{2} \cdot 6 \mathrm{H} 2 \mathrm{O}: 2 \mathrm{~g} / \mathrm{L} ; \mathrm{H}_{3} \mathrm{BO}_{3}: 0.05 \mathrm{~g} / \mathrm{L} ; \mathrm{ZnCl}_{2}$ : $0.05 \mathrm{~g} / \mathrm{L} ; \quad \mathrm{CuCl}_{2} .2 \mathrm{H}_{2} \mathrm{O}: \quad 0.038 \mathrm{~g} / \mathrm{L} ; \quad \mathrm{MnCl}_{2} .4 \mathrm{H}_{2} \mathrm{O}: \quad 0.5 \mathrm{~g} / \mathrm{L}$; $\left(\mathrm{NH}_{4}\right)_{6} \mathrm{Mo}_{7} \mathrm{O}_{24} .4 \mathrm{H}_{2} \mathrm{O}: 0.05 \mathrm{~g} / \mathrm{L} ; \mathrm{AlCl}_{3} .6 \mathrm{H}_{2} \mathrm{O}: 0.09 \mathrm{~g} / \mathrm{L} ; \mathrm{CoCl}_{2} .6 \mathrm{H}_{2} \mathrm{O}$ : $2 \mathrm{~g} / \mathrm{L} ; \mathrm{NiCl}_{2} .6 \mathrm{H}_{2} \mathrm{O}: 0.092 \mathrm{~g} / \mathrm{L} ; \mathrm{Na}_{2} \mathrm{SeO}_{3} .5 \mathrm{H}_{2} \mathrm{O}: 0.164 \mathrm{~g} / \mathrm{L} ; \mathrm{EDTA}: 1 \mathrm{~g} /$ L; Resazurin: $0.2 \mathrm{~g} / \mathrm{L}$; $\mathrm{HCl} 37 \%$ : $1 \mathrm{~mL} / \mathrm{L}$. The composition of this solution was based on the work of Zehnder et al. (1980) and was supplemented to the influent feed by addition of $1 \mathrm{~mL} / \mathrm{L}$.

The superficial velocity was set at $2.8 \mathrm{~m} / \mathrm{h}$ by means of an internal recirculation. $4.1 \mathrm{~L}$ of granular sludge from an industrial UASB reactor treating brewery effluent was used as the inoculum of the EGSB reactor. The volatile suspended solids content was $36.1 \mathrm{gVSS} / \mathrm{L}$, the settling velocity $31.4 \pm 9.8 \mathrm{~m} / \mathrm{h}(n=147)$, and the average equivalent diameter (Deq) was $0.92 \pm 0.43 \mathrm{~mm}(n=294)$. Initial specific acetoclastic activity (SAA) was not detected (<10 $\left.\mathrm{mL} \mathrm{CH}_{4} @ S T P / g V S S . d\right)$. Initial SMA values in the presence of propionate, ethanol and $\mathrm{H}_{2} / \mathrm{CO}_{2}$ were <10 mL CH $@ S T P / g V S S . d, 135 \mathrm{~mL} \mathrm{CH} \mathrm{CH}_{4} @ S T P /$ gVSS.d, and $598 \mathrm{~mL} \mathrm{CH}_{4} @ S T P / g V S S . d$, respectively.

\subsection{Routine analysis}

Chemical oxygen demand (COD) and volatile suspended solids (VSS) were determined according to standard methods (APHA et al., 1989). Biogas flow rate was measured by a "Ritter Milligascounter" (Dr. Ing. Ritter Apparatebau GmbH, Bochum, Germany). Methane content of biogas was determined by gas chromatography using a Porapack Q (100-180 mesh) column with $\mathrm{He}$ as the carrier gas $(30 \mathrm{~mL} / \mathrm{min})$ and a thermal conductivity detector. The temperatures of the detector, injector, and oven were 110,110 and $35^{\circ} \mathrm{C}$, respectively. Volatile fatty acids (VFA) and ethanol were determined by high performance liquid chromatography (Jasco, Japan) with a Chrompack column $\left(6.5 \times 30 \mathrm{~mm}^{2}\right)$. Sulphuric acid $(0.01 \mathrm{~N})$ was used as mobile phase at a flow rate of $0.7 \mathrm{~mL} / \mathrm{min}$. The 
column temperature was set at $60^{\circ} \mathrm{C}$. Detection of VFA and ethanol was made sequentially with an UV detector at $210 \mathrm{~nm}$ and a refraction index (RI) detector, respectively.

\subsection{Sludge sampling and processing}

At different moments of the operation, specifically on days 0 , 38, 60, 80 and 106, biomass samples where collected for SMA and quantitative image analysis measurements.

The maintenance of granular integrity during sludge sampling and processing was crucial. A sampling device was used to take biomass from the reactor without disturbing its morphology. It consisted of a wide bore tube connected to a $100 \mathrm{~mL}$ syringe. It was introduced at the top of the reactor and biomass was collected to the tube, along the reactor, avoiding mechanical stress. The VSS content was determined for all the samples.

Special care was used for sample dilution. Biomass samples must be diluted for image analysis using an optimized dilution factor. Excessive dilution increases the number of objects detected due to a trial-and-error practice. If the dilution is insufficient, the objects will be overlaid. The optimal dilution value was determined as the lowest dilution that enabled the maximum percentage of objects to be recognized. The percentage of recognition is the ratio between the area of objects that are completely inside the image and the total area of objects in the image including those that are at the boundaries and cannot be completely recognized. Depending on sludge concentration and size of aggregates, the optimal dilutions determined for the samples varied between $\frac{1}{20}$ and $\frac{1}{30}$.

\subsection{Image acquisition and analysis}

Three sets of about 100 images were acquired for each sample in order to optimize image quality for detection and quantification of free and protruding filaments, microaggregates (equivalent diameter $<0.2 \mathrm{~mm}$ ) and macroaggregates (equivalent diameter $\geqslant 0.2 \mathrm{~mm}$ ).

Images used to quantify macroaggregates were acquired through visualization on a SZ 40 stereo microscope (Olympus, Tokyo) with $15 \times$ magnification. Images used to quantify filaments and microaggregates were acquired through phase contrast and bright field, respectively, on a Diaphot 300 microscope (Nikon Corporation, Tokyo) with $100 \times$ magnification. All the images were digitized and saved with the help of a CCD AVC D5CE grey scale video camera (Sony, Tokyo) and a DT 3155 frame grabber (Data Translation, Marlboro) with $768 \times 576$ pixel size in 8 bits (256 grey levels) by Image Pro Plus (Media Cybernetics, Silver Spring).

For the filaments and microaggregates, a volume of $35 \mu \mathrm{L}$ from the diluted sample was dispensed on a slide and covered with a $24 \times 24 \mathrm{~mm}$ cover slip for visualization and image acquisition. This volume was exactly covered by the cover slip. Each image corresponded to a volume of $0.0499 \mu \mathrm{L}$. For the macro-aggregates an arbitrary volume was transferred to a Petri dish for visualization and image acquisition. Around 100 images per sample were acquired. Image acquisition of the microaggregates and filaments was obtained by three parallel horizontal passages along the slide at $\frac{1}{4}, \frac{1}{2}$ and $\frac{3}{4}$ of its height for a total of 24 images per slide. With respect to the macroaggregates, the Petri dish was thoroughly screened, from left to right and from top to bottom, and the VSS present in the Petri dish were measured after visualization and image acquisition. For each magnification, the pixels were converted to metric dimensions using a micrometer.

Image processing and analysis was done by means of three programmes developed in Matlab (The Mathworks, Inc., Natick), for filaments, micro, and macroaggregates (Amaral, 2003).

\subsubsection{Filaments programme}

In this programme the grey-scale image was first divided by the background image in order to remove background light differences. A bottom hat filter (Russ, 1995) was then applied to enhance the filaments and small aggregates that have low grey levels. The larger aggregates, which have high grey levels, were subsequently identified on the image resulting from the background elimination step by applying a 10-order closing (to enhance the aggregates) a segmentation at a fixed threshold value, a filling of the resulting binary image (to remove the inner holes in the aggregates) and an erosionreconstruction step to eliminate the debris.

Filaments and small aggregates were then isolated by segmentation at a fixed threshold and by logic subtraction of the mask binary image containing the large aggregates. Then, the small aggregates were eliminated by deleting all the objects smaller than 32 pixels (in area) or with a gyration radius below 1.2 .

The gyration radius is determined as follows (Pons and Vivier, 1999):

$\mathrm{GR}=2 \frac{\sqrt{\mathrm{M}_{2 X}+\mathrm{M}_{2 Y}}}{\mathrm{D}_{\mathrm{Eq}}}$,

where $M_{2 X}$ and $M_{2 Y}$ are the second order moments and $M_{1 X}$ and $M_{1 Y}$ are the first order moments given by

$M_{1 X}=\frac{1}{A} \sum_{n=1}^{N} x_{n}^{i}$

$\mathrm{M}_{1 \mathrm{Y}}=\frac{1}{\mathrm{~A}} \sum_{n=1}^{\mathrm{N}} \mathrm{y}_{n}^{\mathrm{i}}$

$M_{2 X}=\frac{1}{A} \sum_{n=1}^{N}\left(x_{n}^{i}-M_{1 X}\right)^{2}$,

$\mathrm{M}_{2 \mathrm{Y}}=\frac{1}{\mathrm{~A}} \sum_{n=1}^{\mathrm{N}}\left(\mathrm{y}_{n}^{\mathrm{i}}-\mathrm{M}_{1 \mathrm{Y}}\right)^{2}$

and $\left(x_{n}{ }^{i}, y_{n}{ }^{i}\right)$ represent the coordinates of each objects pixels.

The final image contained only filaments that were characterized in terms of their length and number. The filaments image was skeletonized and pruned (Russ, 1995). The filaments length was determined by

$L=N \times 1.122 \times F_{\text {cal }}$, 

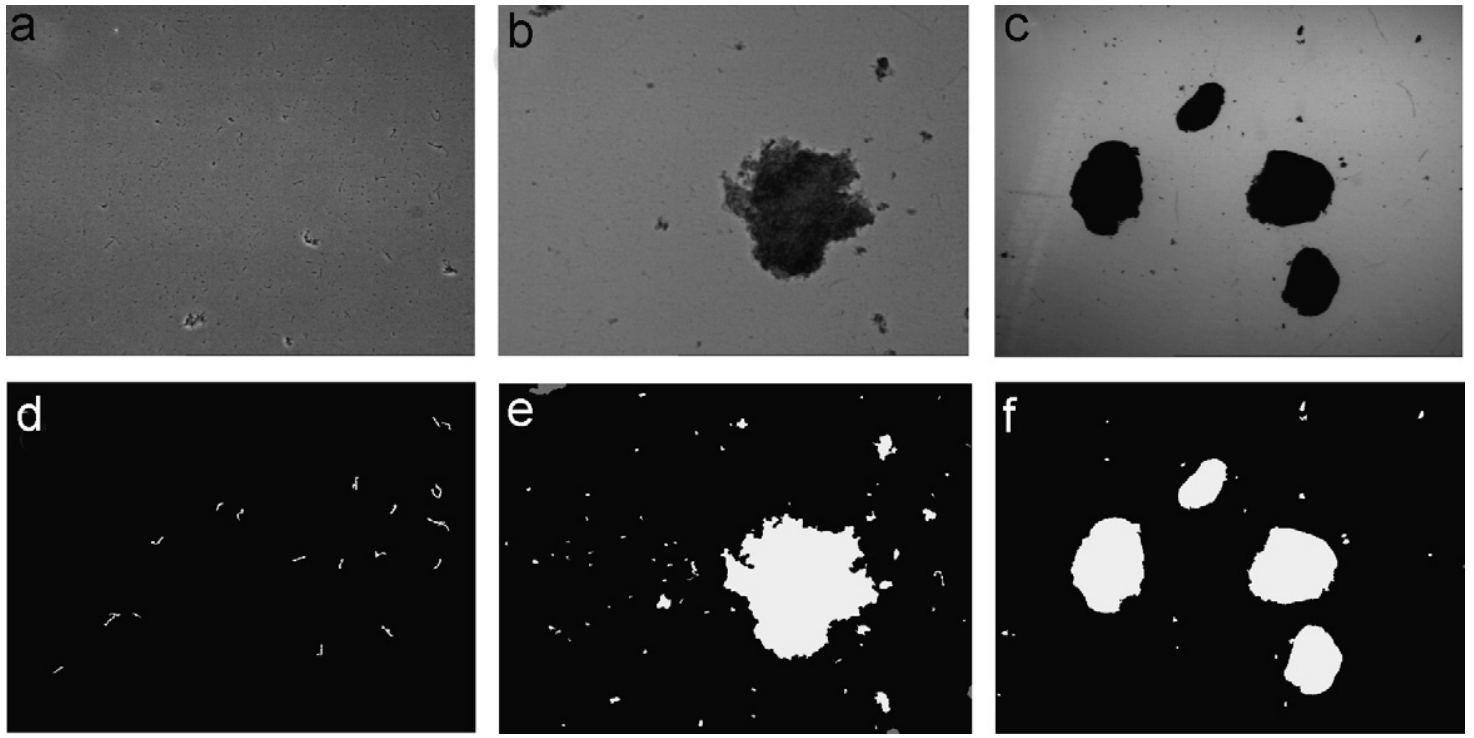

Fig. 1 - Example of original images of filaments (a), microaggregates with a magnification of $100 \times$ (b) and macroaggregates with a magnification of $15 \times(c)$ and the respective final binary images (d)-(f).

where $N$ is the number of pixels of the skeletonized filament and $F_{\text {cal }}$ is the calibration factor $(\mu \mathrm{m} /$ pixel). The different angles of the filaments were homogenized using the factor of 1.1222 (Walsby and Avery, 1996). Finally, the specific total filament length was calculated as $L_{\text {spec }}=L / V_{\text {field }}$ where $V_{\text {field }}$ is the volume (in $\mu \mathrm{m}^{3}$ ) corresponding to the field of view (i.e. the image).

Filaments are not only the dispersed bulk filaments, but include also those that are attached to an aggregate and still have one free extremity.

\subsubsection{Microaggregates programme}

In this programme the grey-scale image was first divided by the background image to remove background light differences. Then, a histogram equalization was performed to enhance the microaggregates followed by an image smoothing Wiener filtering. A lowpass Wiener filtering was used in order to soften the image. The Wiener filter uses a pixelwise adaptive Wiener method based on statistics estimated from a local neighbourhood of each pixel (Glasbey and Horgan, 1995).

The image was then segmented in black (background) and white (objects) by the simultaneous use of a boundary based segmentation and a user chosen or automatically determined threshold segmentation. Objects smaller than $3 \times 3$ pixels (small debris) were then removed and small gaps $(6 \times 6$ pixels or less) were filled on the remaining objects. Subsequently, and in order to remove filaments, all the objects smaller than 2000 pixels in area and with a gyration radius above 1.2 were deleted. Finally, all the objects cut off by the image boundaries were removed, and the morphological characterization of the microaggregates was performed.

\subsubsection{Macroaggregates programme}

In this programme the grey-scale image was first divided by the background image in order to remove background light differences. Next, the image was smoothed by Wiener filtering. The image was then segmented in black (background) and white (aggregates) by threshold segmentation, with a user chosen or automatically determined threshold. Subsequently, small gaps $(6 \times 6$ pixels or less) were filled on the objects, and small debris $(3 \times 3$ pixels or less) were removed. Finally, all the objects cut off by the image boundaries were removed, and the morphological characterization of the macroaggregates was performed. Fig. 1 represents an example of original and binary images obtained from the three programmes.

The parameters determined by these two last programmes are the aggregate Area from which the Equivalent Diameter is calculated:

$D_{\text {eq }}=2 \cdot F_{\text {cal }} \sqrt{\text { Area } / \pi}$

and the total area (A) occupied by aggregates in each image from which the specific area occupied by aggregates is calculated:

$A_{\text {spec }}=\frac{A}{V_{\text {field }}}$.

Finally, a morphological parameter based on the ratio of specific total filament length ( $L_{\text {spec }}$ ) to total projected area of aggregates (LfA) is determined:

$\mathrm{LfA}=\mathrm{L}_{\mathrm{spec}} /\left(A_{\text {spec }}(<0.2 \mathrm{~mm})+A_{\text {spec }(\geqslant 0.2 \mathrm{~mm})}\right)$,

where $A_{\text {spec }(<0.2 \mathrm{~mm})}$ and $A_{\text {spec }}(\geqslant 0.2 \mathrm{~mm})$ are the specific aggregate area ratio for aggregates of equivalent diameter $<$ and $\geqslant 0.2 \mathrm{~mm}$, respectively.

\subsection{SMA assays}

The SMA assays were performed using a pressure transducer technique (Colleran et al., 1992; Alves et al., 2001). SMA was measured against different individual substrates: acetate, propionate, butyrate, ethanol and $\mathrm{H}_{2} / \mathrm{CO}_{2}$. No trace-nutrients were added. 


\subsection{Sectioning, FISH, and confocal imaging}

The method used involved fixing in $4 \%$ paraformaldehyde fixative, embedding, sectioning, dehydrating, hybridization, and imaging. The method of Hugenholtz and Pace (1996) was used for all steps except embedding and sectioning. The embedding and sectioning procedure was displacing in a series of $15 \%$ sucrose and OCT as previously described by Batstone et al. (2004). Granules were sectioned on a cryomicrotome (Leica Microtome 1900).

The following probes were used: Bacteria EUB338all (a combination of EUB338 and EUB338+) (Stahl and Amann, 1991; Daims et al., 1999), and Archaea ARC915 (Stahl and Amann, 1991). The identification protocol of Batstone et al. (2004) was extended by the use of MX825 (Raskin et al., 1994), MB1174 and MG1200 probes (Sekiguchi et al., 1999). Labels used were generally CY-3 for EUB338/EUB338+, FITC for ARC915, CY-3 for MX825, and CY-5 for MB1174 and MG1200. Therefore, in combined images, all bacteria appear red (acidogens and acetogens), hydrogenotrophic methanogens appear cyan, and aceticlastic methanogens (Methanosaetaceae) appear yellow. According to the assumptions in Batstone et al. (2004), acidogenic regions can be identified as bacteria only, acetogenic regions as bacteria associated with hydrogenotrophic archaea, and aceticlastic regions identified as Methanosaetaceae. The probes were used at $20 \%$ formamide. All probes were mixed in a common stock solution at a total probe concentration of $350 \mathrm{ng} / \mu \mathrm{L}$ ( $50 \mathrm{ng} / \mu \mathrm{L}$ for each probe).

Images of the sections were acquired by means of a Zeiss CLSM 510 META system using C-Apochromat $63 \times / 1.2$ Wcorr and PanNeofluor $10 \times / 0.3$ objectives.

\section{Results and discussion}

During the EGSB operation, three operation periods were identified regarding reactor performance, microbial and physical properties of aggregates.

\subsection{Period I}

Period I lasted 40 days. Until day 20 a low methane production around $390 \pm 80 \mathrm{mg} \mathrm{COD}-\mathrm{CH}_{4} / \mathrm{h}$ and a stable effluent acetate COD around $1560 \pm 100 \mathrm{mg}$ acetate-COD/h were observed. Effluent propionate COD showed a significant increasing trend around day 20 and therefore, the influent ethanol COD was decreased from 2900 to $2200 \mathrm{mg}$ COD/h. This corresponded to a decrease in the organic loading rate (OLR) from 6.2 to $4.6 \mathrm{~kg} \mathrm{COD} / \mathrm{m}^{3}$ day. This decrease in OLR improved reactor performance, as shown by the observed decrease in the effluent acetate and propionate COD and the slight increase in the methane production (Fig. 2a).

The presence of propionate in the effluent was unexpected, since ethanol conversion to methane and carbon dioxide normally follows the acetotrophic methanogenesis pathway. However, Laanbroek et al. (1982) indicated that ethanol conversion can also proceed via propionate as an intermediate. In addition, Schink (1984) showed that acetate may be converted to propionate and act as a hydrogen sink by means of hydrogenases. According to Goldberg and Cooney (1981), the bacteria involved in ethanol degradation may also act cooperatively with homoacetogenic bacteria in propionate formation from $\mathrm{C}_{1}$ compounds.

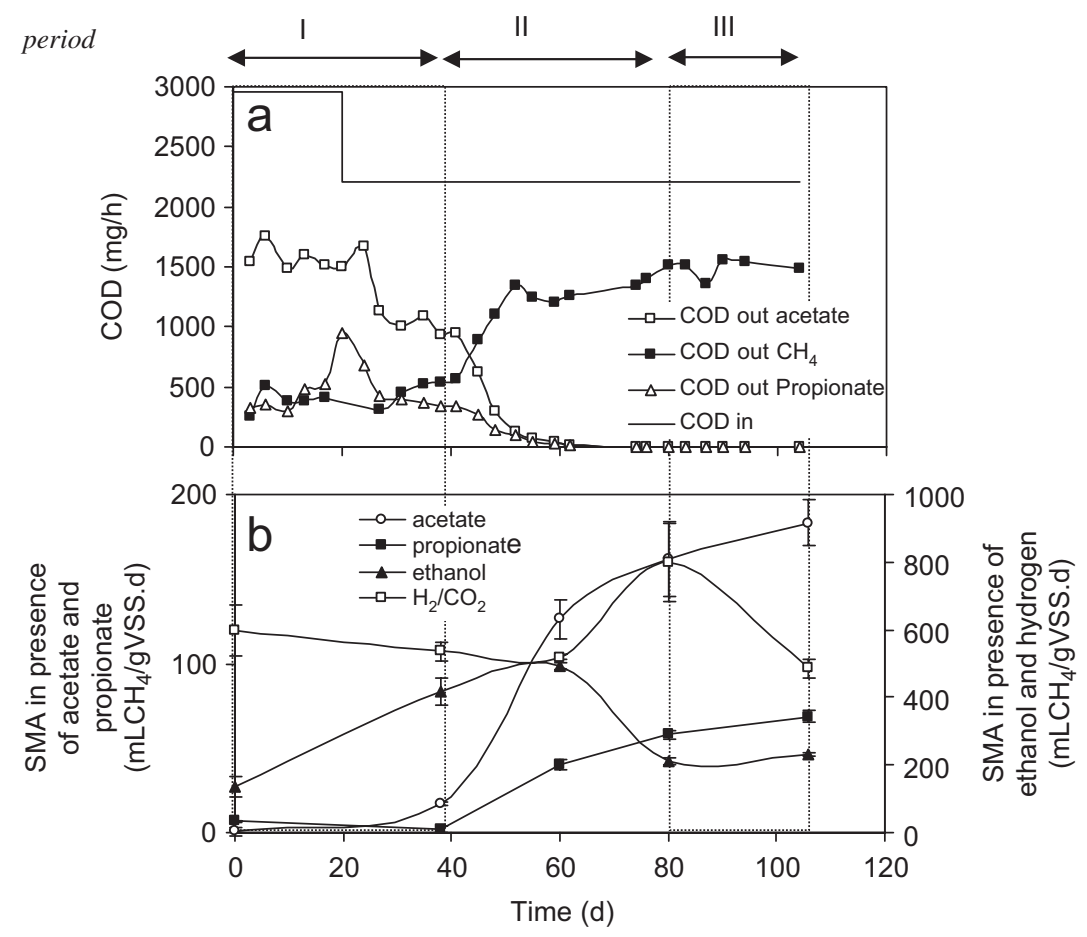

Fig. 2 - Time course of reactor performance (a) and specific metanogenic activity in the presence of acetate, propionate, butyrate, ethanol, and $\mathrm{H} 2 / \mathrm{CO} 2$ (b). The volume of methane is expressed in STP conditions. 
The SAA was not detected during the period I but showed an initial trend to increase by day 40 (Fig. 2b). Therefore, It can be concluded that the methane produced during this stage of operation was mainly due to the hydrogenotrophic methanogenic activity. As expected, the specific methanogenic activity with ethanol as substrate increased steadily during this period. Significant granule fragmentation was observed in this period as shown by the a decrease in the percent of projected area of aggregates with an equivalent diameter larger than $1 \mathrm{~mm}$ (Fig. 3a) and a corresponding increase in the percent of aggregates with equivalent diameters in the range $0.1-1 \mathrm{~mm}$. On the other hand, an effective filaments release was observed since the filaments length per VSS unit increased from 0.6 to $6.9 \mathrm{~m} / \mathrm{mg}$ VSS.

The phenomena of filaments release and fragmentation combined to increase the filaments length/aggregates pro- jected area (LfA). These structural changes were acco mpanied by a decrease in the amount of VSS per projected area of aggregates (Fig. 3c). When the sludge sample is free of filaments, this parameter can be an indirect estimation of aggregates density. However, in this case, the total free filaments length increased between 0.6 and $6.9 \mathrm{~m} / \mathrm{mg}$ VSS (data not shown), and therefore, the decrease in the VSS/total area combines the effect of a decrease in density and an increase in the dispersed (filamentous) VSS. A decrease in density could be explained by the onset of biogas production, as was observed at the end of this period.

Although the inoculum was composed of dense particles, the absence of acetoclastic activity constituted a severe constraint in its application at industrial scale. The higher density exhibited by the initial sludge in comparison with

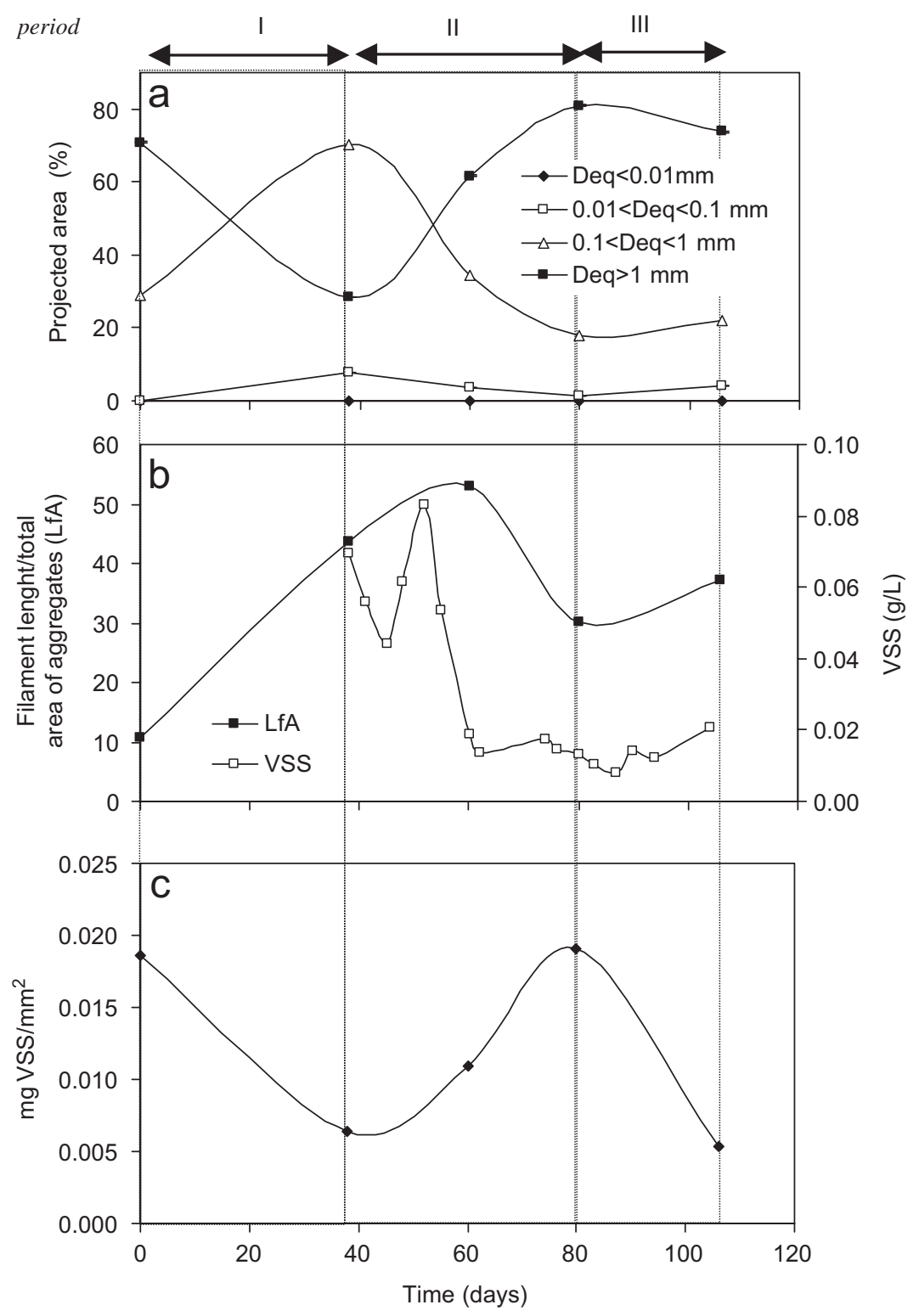

Fig. 3 - Time course of morphological properties. Percentage of projected area within different size ranges (a), LfA and effluent VSS (b) and apparent density measured by $\mathrm{mg} \mathrm{VSS} / \mathrm{mm}^{2}$ (c). 

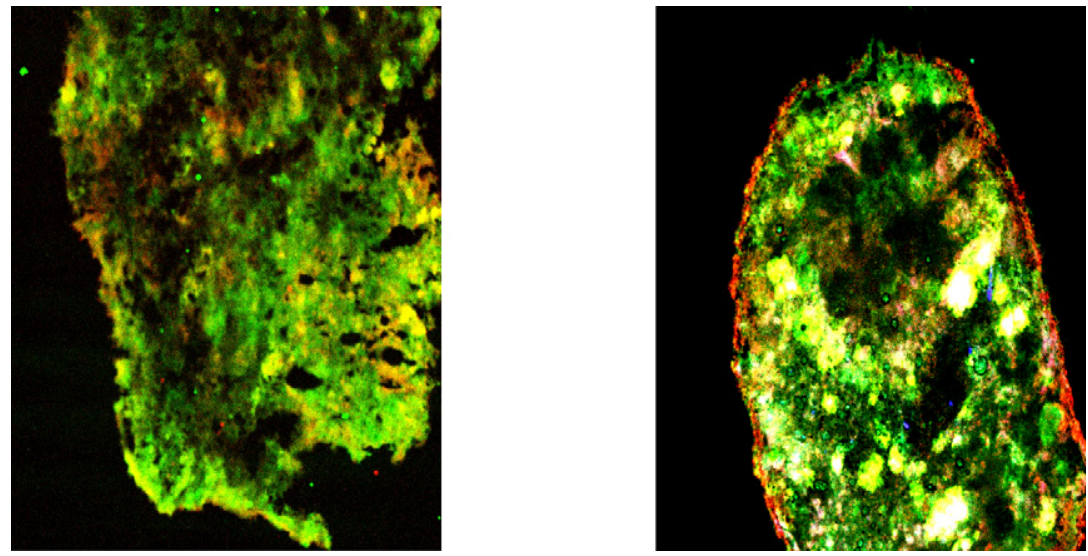

Fig. 4 - Example of two confocal images of FISH hybridized granules taken from the inoculum of the EGSB reactor (a) and at the end of the operation period (b). Red-acetogenic and acidogenic bacteria; cyan-Hydrogenotrophic Methanogens; yellow-Methanosaeta spp.; green-Low hybridisation.

sludge collected on day 40 (Fig. 3c) could be the result of low biogas flow through the particles. It can be also hypothesized that the filamentous core (mainly composed of Methanosaeta like organisms) was probably more fragile than in active granules. On the other hand, in large aggregates, the mass transfer of acetate towards the inner parts of the granules should be controlled by diffusion, especially in dense aggregates where convection is unlikely to occur. It is suggested that the granule breakdown probably occurred at weaker or inert regions and the growth of filamentous bacteria outside the granular structure were advantageous in terms of mass transport of substrates and products and had a positive effect in the recovery of the acetoclastic activity.

\subsection{Period II and III}

During period II, the methane production increased and acetate and propionate concentration in the effluent decreased (Fig. 2a). The SAA increased steadily from $17 \pm 1$ at day 40, to $162 \pm 22 \mathrm{~mL} \mathrm{CH}_{4} @ S T P / g V S S . d$ at day 80. SMA in the presence of ethanol decreased between day 60 and 80 and an inverse profile was observed for the specific methanogenic activity in presence of $\mathrm{H}_{2} / \mathrm{CO}_{2}$ (Fig. 3b) which peaked at day 80 . It is interesting to observe in Fig. $3 \mathrm{c}$ that the VSS per projected area was also a maximum at day 80 . This suggests that a higher degree of density and compaction was beneficial for interspecies hydrogen transfer thereby increasing the hydrogenotrophic methanogenic activity.

After day 60, a selection of aggregates larger than $1 \mathrm{~mm}$ was noticed, likely induced by washout or growth of the smaller aggregates $\left(0.1 \mathrm{~mm}<D_{\text {eq }}<1 \mathrm{~mm}\right)$. The washout hypothesis seems to be supported by the effluent VSS values which were in the range of 44-83 mg VSS/L between days 40 and 52, and decreased afterwards to values around 10-20 mg VSS/L. The washout event was certainly helped by the increase of biogas production after day 40 , which induces an erosion effect on the granules surface promoting the presence of free filaments and small aggregates in the bulk, and subsequent washout.
The filaments length per projected area (LfA) increased until day 60 achieving a maximum value of $54 \mathrm{~mm}^{-1}$ (Fig. 3b) and decreased afterwards. This increase in LfA, simultaneous with the dominance of larger aggregates, clearly suggests a significant release of free (or protruding) filaments between days 40 and 60 . The LfA decrease between days 60 and 80 (Fig. 3b), the peak in density (Fig. 3c) and the dominance of particles with equivalent diameters larger than $1 \mathrm{~mm}$ at day 80 (Fig. 3a), evidence that anaerobic sludge was at that point mostly structured in dense and large aggregates with insignificant filamentous dispersed forms. After day 80, and although the biogas production was stable, some structural changes could be observed. The VSS/area decreased from 0.02 to $0.005 \mathrm{mg} \mathrm{VSS} / \mathrm{mm}^{2}$, and the total free filaments length per VSS unit increased from 1.6 to $6.9 \mathrm{~m} / \mathrm{mg}$ VSS (data not shown). Therefore, it is likely to expect that the VSS concentration of the aggregates (excluding the dispersed fraction of VSS) decreased in this period. This suggests a decrease in aggregates density and a change to a more loosely structure which can be related to a higher biogas flow potential due to the increase in the acetoclastic activity which was observed in the same period. On the other hand, the concomitant decrease in the hydrogenotrophic activity can be result of impaired interspecies hydrogen transfer in loose aggregates.

During the final 20 days of operation, reactor performance was stable with an efficient methane production and no detectable acetate or propionate concentration in the effluent. SAA increased to $183 \pm 14 \mathrm{~mL} \mathrm{CH}_{4} @ S T P / g V S S$.day at day 106. The size distribution of aggregates was stable during this period.

Fig. 4 compares two examples of CSLM FISH images of the inoculum and the sludge present in the EGSB reactor at the end of the operation. It is evident that initial granules showed a mixture of different populations without a clear organization (Fig. 4a). The final granules (Fig. 4b) showed an external layer of acidogenic/acetogenic bacteria and a strong presence of Methanosaeta in their interior, forming clusters, as previously shown by Gonzalez-Gil et al. (2001). The increase in Methanosaeta presence was expected due to the increase in the SAA. 


\section{Conclusions}

1. Feeding ethanol as the sole organic carbon source to a lab scale EGSB reactor promoted an increase in the SAA from $<10$ to $183 \pm 14 \mathrm{~mL} \mathrm{CH} \mathrm{CH}_{4} @ S T P / g V S S$.day, after 106 days. Propionate was an intermediate of ethanol degradation.

2. Phenomena of granular fragmentation/erosion, growth and filaments release were identified and quantified during the process of acetoclastic activity revival.

3. The onset of biogas production in the lab-scale EGSB reactor was simultaneous with granular breakdown by fragmentation/erosion and an increase in free or protruding filaments from 0.6 to $6.9 \mathrm{~m} / \mathrm{mg}$ VSS.

4. From the results presented it may be suggested that the fragmentation observed could have promoted the onset of SAA recovery, likely due to the decrease of mass transfer limitations between the bulk and the cores of the newly formed small particles.

\section{Acknowledgements}

We gratefully acknowledge the financial support to P. ArayaKroff, J.C. Costa and Ângela Abreu through the Grants SFRH/ BD/3187/2000, SFRH/BD/13317/2003, and the Project POCTI/ BIO/37934/2001, respectively, from the Fundação para a Ciência e a Tecnologia (Portugal). Special thanks to Dr. Damien Batstone (DTU, Lyngby, Denmark) for help with confocal microscopy and to Dr. Anthony Danko for English revision.

R E F E R E N C E S

Alves, M.M., Cavaleiro, A.J., Ferreira, E.C., Amaral, A.L., Mota, M., da Motta, M., Vivier, H., Pons, M.-N., 2000. Characterization by image analysis of anaerobic sludge under shock conditions. Water Sci. Technol. 41, 207-214.

Alves, M.M., Mota Vieira, J.A., Álvares Pereira, R.M., Pereira, M.A., Mota, M., 2001. Effects of lipids and oleic acid on biomass development in anaerobic fixed bed reactors. Part I: biofilm growth and activity. Water Res. 35 (1), 255-263.

Amaral, A.L., 2003. Image analysis in biotechnological processes: application to wastewater treatment. Ph.D. Dissertation, University of Minho, Portugal $\langle$ http://hdl.handle, net/1822/4506 >.

Amaral, A.L., Pereira, M.A., da Motta, M., Pons, M.-N., Mota, M., Ferreira, E.C., Alves, M.M., 2004. Development of image analysis techniques as a tool to detect and quantify morphological changes in anaerobic sludge: II. Application to a granule deterioration process triggered by contact with oleic acid. Biotechnol. Bioeng. 87, 194-199.

APHA, AWWA, WPCF, 1989. Standard Methods for the Examination of Water and Wastewater, 17th ed. American Public Health Association, Washington, DC.

Araya-Kroff, P., Amaral, A.L., Neves, L., Ferreira, E.C., Pons, M.-N., Mota, M., Alves, M.M., 2004. Development of image analysis techniques as a tool to detect and quantify morphological changes in anaerobic sludge: I. Application to granulation process. Biotechnol. Bioeng. 87, 184-193.

Batstone, D.J., Keller, J., Blackall, L.L., 2004. The influence of substrate kinetics on the microbial community structure in granular anaerobic biomass. Water Res. 38 (6), 1390-1404.

Colleran, E., Concannon, F., Goldem, T., Geoghegan, F., Crumlish, B., Killilea, E., Henry, M., Coates, J., 1992. Use of methanogenic activity tests to characterize anaerobic sludges, screen for anaerobic biodegradability and determine toxicity thresholds against individual anaerobic trophic groups and species. Water Sci. Technol. 25, 31-40.

Daims, H., Bruhl, A., Amann, R., Schleifer, K.H., Wagner, M., 1999. The domain-specific probe EUB338 is insufficient for the detection of all bacteria: development and evaluation of a more comprehensive probe set. Syst. Appl. Microbiol. 22 (3), 434-444.

Glasbey, C.A., Horgan, G.W., 1995. Image Analysis for the Biological Sciences. Wiley, Chichester.

Goldberg, I., Cooney, C.L., 1981. Formation of short chain fatty acids by a mixed culture of bacteria. Appl. Environ. Microbiol. 41, 148-154.

Gonzalez-Gil, G., Lens, P.N.L., Van Aelst, A., Van As, H., Versprille, A.I., Lettinga, G., 2001. Cluster structure of anaerobic aggregates of an expanded granular sludge bed reactor. Appl. Environ. Microbiol. 67, 3683-3692.

Hugenholtz, P., Pace, N.R., 1996. Identifying microbial diversity in the natural environment: a molecular phylogenetic approach. Trends Biotechnol. 14 (6), 190-197.

Hulshoff Pol, L.W., Lopes, S.I.D., Lettinga, G., Lens, P.N.L., 2004. Anaerobic sludge granulation. Water Res. 38 (6), 1376-1389.

Laanbroek, H.J., Abee, T., Voogd, I.L., 1982. Alcohol conversions by Desulfobulbus procionicus Lindhorst in the presence and absence of sulphate and hydrogen. Arch. Microbiol. 133, 178-184.

Lettinga, G., 1995. Anaerobic digestion and wastewater treatment systems. Antonie van Leeuwenhock 67, 3-28.

Pons, M.N., Vivier, H., 1999. Biomass quantification by image analysis. Adv. Biochem. Eng. Biotechnol. 66, 133-184.

Raskin, L., Stromley, J.M., Rittmann, B.E., Stahl, D.A., 1994. Groupspecific 16S rRNA hybridization probes to describe natural communities of methanogens. Appl. Environ. Microbiol. 60 (4), 1240-1323.

Russ, C.R., 1995. The Image Processing Handbook. CRC Press, Boca Raton, FL.

Schink, B., 1984. Fermentation of 2,3-butanediol by Pelobacter carbinolicus sp. nov. and evidence for propionate formation from C2 compounds. Arch. Microbiol. 137, 33-41.

Sekiguchi, Y., Kamagata, Y., Nakamura, K., Ohashi, A., Harada, H., 1999. Fluorescence in situ hybridization using $16 \mathrm{~S}$ rRNAtargeted oligonucleotides reveals localization of methanogens and selected uncultured bacteria in mesophilic and thermophilic sludge granules. Appl. Environ. Microbiol. 65 (3), 1280-1288.

Stahl, D.A., Amann, R., 1991. Development and application of nucleic acid probes. In: Stackebrandt, E., A.M.G. (Eds.), Nucleic Acid Techniques in Bacterial Systematics. Wiley, New York, NY, pp. 205-248.

Walsby, A.E., Avery, A., 1996. Measurement of filamentous cyanobacteria by image analysis. J. Microbiol. Methods 26, 11-20.

Zehnder, A.J.B., Huser, B.A., Brock, T.D., Wuhrmann, K., 1980. Characterization of an acetate-decarboxylating, non-hydrogen-oxidizing methane bacterium. Arch. Microbiol. 124, 1-11. 